\title{
Nasbinals
}

\section{Laurent Fau}

Édition électronique

ISSN : 2114-0502

Éditeur

Ministère de la culture

Référence électronique

Laurent Fau, «Nasbinals », ADLFI. Archéologie de la France - Informations [En ligne], LanguedocRoussillon, mis en ligne le 01 mars 2004, consulté le 02 mai 2019. URL : http:/l

journals.openedition.org/adlfi/11728

Ce document a été généré automatiquement le 2 mai 2019.

(c) Ministère de la Culture et de la Communication, CNRS 


\section{Nasbinals}

\section{Laurent Fau}

Date de l'opération : 1996 (SD)

Inventeur(s) : Fau Laurent

1 Le site des Places-Hautes s'intègre dans une série d'habitats désertés découverts sur le plateau de l'Aubrac. Une approche pluridisciplinaire de cette région, à l'époque médiévale, a été engagée. Le projet collectif de recherche, déjà présenté, en 1995, lors de la réalisation d'un sondage sur le site du Barthas (Nasbinals, Lozère), a pour but d'étudier le terroir d'Aubrac lié à la seigneurie ecclésiastique de la Domerie. trois grands axes ont été définis et s'articulent ainsi : l'habitat temporaire, l'habitat permanent et l'activité artisanale. Notre recherche permet d'aborder ce terroir en privilégiant à la fois l'étude de l'habitat et le paysage par le biais de l'archéologie, l'histoire, l'ethnologie et les sciences paléoenvironnementales.

2 Concernant l'habitat, notre choix s'est porté sur un site tout à fait exceptionnel, il s'agit d'une unité agricole, un «mas» et non comme à l'accoutumée un hameau d'une quinzaine de bâtisses en moyenne.

3 Les structures se présentent sous la forme de deux constructions composant un L renversé. Le premier bâtiment comporte deux parties, l'une servant d'étable l'autre réservée à l'habitation; le second se trouve à sa perpendiculaire. Grâce à cette disposition, les ouvertures restent à l'abri des intempéries. Un four à pain et une source viennent compléter ce plan de "ferme modèle ».

4 Les caractères architecturaux de ces bâtiments mettent en évidence des spécificités montagnardes adaptées à un climat rude et une altitude de $1240 \mathrm{~m}$. Le site est implanté dans une légère combe, orientée au sud, le plan des bâtiments est conçu pour bénéficier du chauffage animal et s'occuper du bétail sans sortir. L'intérieur des bâtisses est surcreusé, les entrées ont reçu un aménagement extérieur. Enfin, les murs, d'une largeur moyenne de $1,50 \mathrm{~m}$, possèdent un blocage de terre servant d'isolant.

5 Si l'architecture est très riche d'enseignement, il n'en va pas de même pour la stratigraphie et le mobilier découvert. En effet, les coupes de terrains sont très sommaires 
et le mobilier céramique mis au jour ne donne que très peu d'indices chronologiques faute de référentiel pour cette région, seule l'attribution de ces vestiges à l'époque médiévale est certaine. Le recours à la datation radiocarbone nous permet d'être plus précis et propose la datation suivante: Ly. 8110 : $945 \mathrm{BP} \pm 40 \mathrm{BP}$ soit en âge calibré 1025-1191 apr. J.-C.

6 Le site des Places-Hautes est l'un des rares exemples en France d'exploitation agricole médiévale située en milieu montagnard, ce qui lui confère un intérêt tout particulier.

INDEX

Index géographique : Languedoc-Roussillon, Lozère (48), Nasbinals Index chronologique : Moyen Âge

operation Sondage (SD) 